\title{
Investigation of the Relationship Between the Core Temperature of Hazelnuts and Ambient Conditions in the Drying Process
}

\author{
Cevdet DEMIRTAŞ ${ }^{1}$, Merdin DANIŞMAZ ${ }^{2 *}$ \\ ${ }^{1}$ Karadeniz Technical University, Engineering Faculty, Mechanical Engineering Department, 61080, Trabzon-Turkey \\ demirtas@ktu.edu.tr- ORCID: 0000-0002-9099-3573 \\ ${ }^{2}$ Kırşehir Ahi Evran University, Faculty of Engineering and Architecture, Mechanical Engin. Dep., Kırşehir-Turkey \\ * Corresponding Author : m.danismaz@ ahievran.edu.tr- ORCID: 0000-0003-2077-9237
}

\section{Article Info:}

DOI: $10.22399 /$ ijcesen.906196

Received: 28 February 2020

Accepted: 31 March 2021

\section{Keywords}

Hazelnut drying

Drying rate

Drying temperature

\begin{abstract}
:
Hazelnut, which is one of the major export products in Turkey, can be generally evaluated and preserved in dried form. There are difficulties encountered in keeping its internal temperature and humidity constant at desired values because it is commonly exposed to solar energy and dried in outdoor environment. Especially due to rainy and variable weather conditions, it is possible to decay and decompose the inner hazelnut without full drying. Because of improper drying, hazelnuts are known to lose their nutritional value. In this study, the attitude of hazelnut was observed in different ambient conditions and the drying temperatures in hazelnut drying processes performed under laboratory conditions. For this purpose, insulated drying booths for experimental setup were created and air circulation was provided for forced convection by fans. Approximately equal sized hazelnuts were placed in the cabin. The main properties of hazelnuts before and after conditioning were recorded for each experiment. The internal temperature, surface temperature and mass loss of the hazelnut were evaluated together. Drying attitudes were recorded for different types of hazelnuts (round, pointed and long). The optimum ambient conditions and drying temperatures were determined during hazelnut drying process. Drying times at 25-50 ${ }^{0} \mathrm{C}$ temperature were determined for hazelnuts with $60 \%$ relative humidity under ambient air conditions at $3 \mathrm{~m} / \mathrm{s}$ rate. It has been understood that keeping the drying speed and temperature high or low causes uncontrolled and insufficient drying. It has been observed that different drying conditions can be applied depending on hazelnut storage properties.
\end{abstract}

\section{Introduction}

Turkey, the leader of world hazelnut production, accounts for $68,8 \%$ of world hazelnut production. Although consumption of hazelnut is very limited, dry hazelnut consumption corresponds to a large part of hazelnut market. The dry hazelnut quality varies depending on the conditions of the hazelnut, depending on the growing conditions as well as the drying conditions. For this reason, work continues to determine the best hazelnut drying conditions. Hazelnut, together with other nuts, is consumed as a common snack food. They are also used in the main sweet and savory dishes that represent a valuable component of a healthy Mediterranean diet $[1,2,3]$. According to many clinical trials, regular intake of nuts is associated with a reduced risk of various diseases such as cardiovascular disease, specific cancer types and neurode generative disorders such as an improved memory, learning and cognitive ability $[4,5]$. Some studies $[6,7]$ that examine the drying of hazelnut, which is a biological porous structure, indicate that the diffusion coefficient changes during drying depending on the temperature and nourishment.

\section{Material and Method}

\subsection{The Experimental Setup}

Experiments were carried out in a laboratory scale convective air dryer duct as shown in Figure 1. There are one electric motor, fan, flow trimmer and 
heater in the experiment setup. The channel is 12 $\mathrm{cm}$ square in cross section and $135 \mathrm{~cm}$ in length. The perimeter of the duct is insulated to prevent heat losses to the surround. The mass flow rate of the drying air was controlled by a fan at different engine speeds to determine the $\mathrm{u}$ value ranging from $0,2 \mathrm{~m} / \mathrm{s}$ to $0,6 \mathrm{~m} / \mathrm{s}$ at the channel entrance. The air heated at the inlet of the channel passes through the test zone, allowing the sample of the nut in the axial center to be dried by convection. A thermometer and a U-manometer channel are connected to measure the temperature and pressure drops in the channel. In addition, a data logger was used throughout the experiments to record the temperature changes in the sample and to record the mass losses.

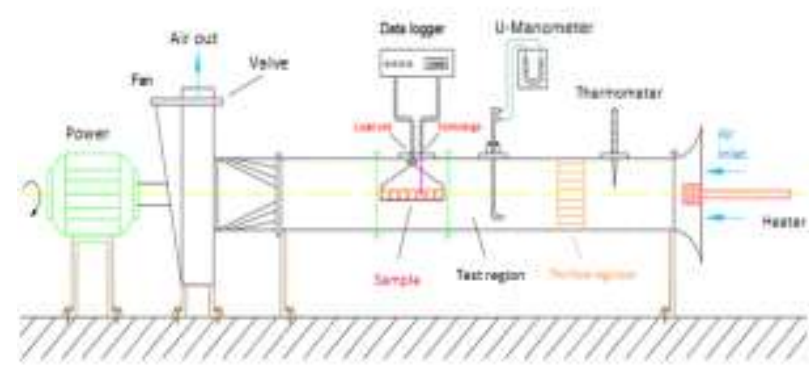

Figure 1. Schematic view of the experimental setup

\subsection{Sphericity Ratio for Hazelnut}

The statistical study done on 100 hazelnut samples selected from the test samples determined the sphericity ratio of the hazelnut. According to the geometry in Figure 1, the global ratio of the nut to the nut was determined [8].

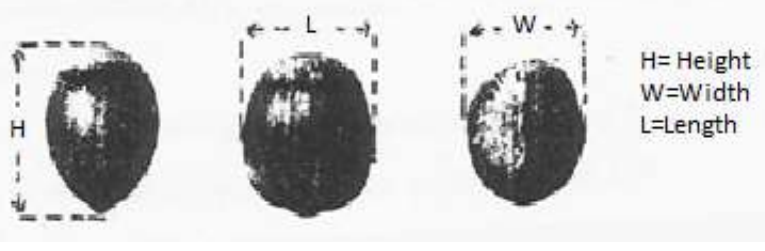

Figure 2. Hazelnut dimensions considered for shape value

The average diameter of the hazelnut, da, can be determined with the height $\mathrm{H}$, the width $\mathrm{W}$, and the Length $\mathrm{K}$ as

$$
d_{a}=\frac{(H+W+L)}{3}
$$

The actual volume of the hazelnut was determined by the amount of mercury overflowing when immersed in the bolt.

$$
\varphi=\frac{A_{0}}{A_{v}} \frac{\pi\left(6 V_{v} / \pi\right)^{\frac{2}{3}}}{A_{v}}
$$

Where $A_{0}$ is the equivalent surface area, $A_{v}$ is the surface area of the hazelnut, and $V_{v}$ is the volume of hazelnut. In this way, the calculated globality rate was determined as $91 \%$ on average.

\subsection{Moisture Determination and Balance Moisture}

The moisture content in the hazelnut was determined before and at the end of the experiments. After grinding with the shells of the samples taken from the hazelnut parties, the humidity content was determined by using the Ohaus MB-45 model moisture analyzer for determining the amount of dry matter. The equilibrium moisture values of the dried hazelnut are determined in closed glass jars containing saturated solutions of various chemical substances, keeping the environment at different relative humidity seen Table 1 . The jars are made in two sections. Chemical solutions are placed on the bottom of the jars. Sieves were placed in the middle of the jars and samples of hazelnuts placed in petri dishes were placed on top of the sieves. The jar covers are tightly closed and placed in a constant temperature environment.

Table 1. Certain substances that hold the environment in which saturated solutions in water are present

\begin{tabular}{|c|c|c|c|c|}
\hline Salt Name & $\begin{array}{l}\text { Chemical } \\
\text { Formula }\end{array}$ & $\begin{array}{l}\text { Relative } \\
\text { humidity } \\
(\%)\end{array}$ & $\begin{array}{l}\text { Quantity } \\
\text { (gr) }\end{array}$ & \begin{tabular}{|l|} 
The \\
amount \\
of water \\
(lt) \\
\end{tabular} \\
\hline Potassium acetate & $\mathrm{CHCOO}$ & 22 & 200 & 65 \\
\hline Magnesium & $\mathrm{MgCl}_{2}$ & 32 & 200 & 25 \\
\hline Potassium & $\mathrm{K}_{2} \mathrm{CO}_{3}$ & 41 & 200 & 30 \\
\hline Magnesium nitrate & $\operatorname{Mg}\left(\mathrm{N}_{3}\right)_{2}$ & 53 & 200 & 80 \\
\hline Sodium bromide & $\mathrm{NaBr}$ & 57 & 200 & 50 \\
\hline Sodium nitrate & $\mathrm{NaNO}_{3}$ & 66 & 200 & 50 \\
\hline Stronsyum & $\mathrm{SrCl}$ & 70 & 200 & 60 \\
\hline Sodium chloride & $\mathrm{NaCl}$ & 5 & 200 & 60 \\
\hline Ammonium & $(\mathrm{NH})_{2}(\mathrm{~S}$ & 90 & 200 & 60 \\
\hline Potassium & $\mathrm{KCl}$ & 67 & 200 & 90 \\
\hline Barium chloride & $\mathrm{BACl}_{2}$ & 90 & 250 & 70 \\
\hline Lidyum chloride & $\mathrm{LiCl}$ & 11 & 200 & 70 \\
\hline
\end{tabular}
at different relative humidity [9].

\subsection{Heat Transfer Modeling}

With the assumption that the structure of the nut is a multi-layered sphere, studies first focus on numerical solutions of heat transfer in a one- 
dimensional transient regime in layered spheres. The numerical solution of the heat transfer in a single-layered culvert is given in [9]. In the study, heat transfer in three-layered cullet with numerical method was obtained for various parameters. The same material values are given for the layers and are calculated as a single layer sphere and the results are consistent with the values given in $[11,12]$. In the experiments, the cooling curves were drawn using dried chestnuts. Wherein the moisture inside nut has the value of the equilibrium moisture. . In the mathematical model considered, single hazelnut grain is modeled with a layered sphere approach consisting of eutectic + air + crust. The number of $\mathrm{Ra}(\mathrm{Ra}=\mathrm{Gr} * \mathrm{Pr})$ was calculated in the air layer for chubby hazelnut. Since Ra> 1708, it is assumed that heat conduction is only conduction since there is no air movement in this layer.

$$
\frac{\partial^{2} T}{\partial r^{2}}+\frac{2}{r} \frac{\partial T}{\partial r}=\frac{1}{a} \frac{\partial T}{\partial t}
$$

Hence,

$$
\frac{\partial T}{\partial t}=a\left(\frac{\partial^{2} T}{\partial r^{2}}+\frac{2}{r} \frac{\partial T}{\partial r}\right)
$$

Where $a\left(=k / \rho c_{p}\right)$ is the diffusion coefficient. Boundary conditions must be taken into consideration in order to determine the temperature distribution in the hazelnut from $r=0$ to $r=R_{l}$. Related correlation is written as follows:

I. From Fourier's law at $r=0$,

$$
\frac{\partial T}{\partial r}=0
$$

II. From Fourier's law at $r=R_{3}$,

$$
-\left.k_{3} \frac{\partial T}{\partial r}\right|_{r=R_{3-3}}=-\left.k_{2} \frac{\partial T}{\partial r}\right|_{r=R_{3-2}}
$$

III. From Fourier's law at $\mathrm{r}=\mathrm{R}_{2}$,

$$
-\left.k_{2} \frac{\partial T}{\partial r}\right|_{r=R_{2-2}}=-\left.k_{1} \frac{\partial T}{\partial r}\right|_{r=R_{2-1}}
$$

IV. From Fourier's law at $\mathrm{r}=\mathrm{R}_{1}$,

$$
\dot{q}=h\left(T_{y}-T_{\infty}\right)=-\left.k_{1} \frac{\partial T}{\partial r}\right|_{r=R_{1}}
$$

In these equations, $\dot{q}$ is the heat flux. $\mathrm{T}_{\mathrm{y}}$ and $\mathrm{T}_{\infty}$ shows the surface temperature and the ambient air temperature respectively. $\mathrm{R}_{(3-3),} \mathrm{R}_{(3-2)}$ and $\mathrm{R}_{(2-1)}$ represent the radius on the right side of the third layer, the radius of the second layer side and the radius on the side of the first layer respectively.

These expressions can be obtained in dimensionless form using the following relations.

$$
\theta=\frac{T-T_{\infty}}{T_{0}-T_{\infty}}, r^{*}=\frac{r}{R_{1}}, \tau=\frac{a_{1} t}{R_{1}^{2}}, a_{i}^{*}=\frac{a_{i}}{a_{1}}
$$

Where $a_{i}$ represents the heat dissipation coefficients in the layers.

Thus, the equation 4 can be written as

$$
\frac{\partial T}{\partial t}=a_{i}^{*}\left(\frac{\partial^{2} T}{\partial r^{* 2}}+\frac{2}{r^{*}} \frac{\partial T}{\partial r^{*}}\right)
$$

If the following definitions are made for border conditions,

$$
\frac{\partial T}{\partial r^{*}}=0,-k_{2-3}^{*}=\frac{k_{2}}{k_{3}} \text { ve } k_{1-2}^{*}=\frac{k_{1}}{k_{2}}
$$

The following dimensionless expressions can be obtained.

$$
\begin{aligned}
& -\left.k_{2-3}^{*} \frac{\partial \theta}{\partial r^{*}}\right|_{r=R_{3-2}}=\left.\frac{\partial \theta}{\partial r^{*}}\right|_{r=R_{3-3}} \\
& -\left.k_{1-2}^{*} \frac{\partial \theta}{\partial r^{*}}\right|_{r=R_{2-1}}=\left.\frac{\partial \theta}{\partial r^{*}}\right|_{r=R_{2-2}}
\end{aligned}
$$

Using the $r^{*}$ and $\theta$ terms in the equations, a dimensionless expression can be developed based on the number of Biot as follow;

$$
h \theta=-\frac{k_{1}}{R_{1}} \frac{\partial \theta}{\partial r^{*}}
$$

Bi number for the sphere is written as

Hence,

$$
B i=-\frac{h R_{1}}{k_{1}}
$$

$$
\frac{\partial \theta}{\partial r^{*}}=B i \theta
$$

Numerical solutions of differential equations are different for parabolic and elliptic differential equations. Since the heat transfer is in the transient regime and the temperature in the sphere changes only radially, the differential equation expressed in Equation 10 is a two-dimensional parabolic differential equation. The implicit solution method and the Crank-Nicolson method are used after the differential equation is made the finite difference equation by using the finite difference method. The 
resulting finite difference equation generally takes the following form in the solution domain:

$$
A_{j} \theta_{j-1}+B_{j} \theta_{j}-C_{j} \theta_{j+1}=D_{j}
$$

Where $A_{j}, B_{j}, C_{j}$ ve $D_{j}$ are some coefficients for the corresponding expressions. The solutions of these equations are done by the Gauss-Elimination TDMA method. In order to remove the discontinuity at the center of the sphere, $r=0$, some derivative equations can be derived from the contact surfaces of the layers using the derivative condition. The results obtained for the various parameters are given in graphical form using the implicit solution method $[11,12]$.

\subsection{Calculation method applied in determination of mass transfer}

For each experiment, real hazel weights were obtained from relative hazel weight of hazelnut parties. Full dry hazel weights were determined using an oven. The values obtained from the experiments are plotted with time with respect to the hazel party weights with the help of the following relation.

$$
f(t)=\frac{M_{t}-M_{e}}{M_{0}-M_{e}}
$$

Where $M_{t}$, is the weight of the hazelnut $[13,14]$.

\section{Results and Discussion}

The average dimensions of the hazelnut samples and the experimental conditions are given below in the process of determining the heat transfer parameters.

$R e=45500, \quad R_{\text {hazelnut }}=0,00868 \mathrm{~m}, \quad T_{\text {medium }}=18{ }^{\circ} \mathrm{C}$, $W_{\text {hazelnut }}=\% 6,6, C=0,007721 \mathrm{l} / \mathrm{s}, J_{i}=1,4116723$

For the selected plump hazelnut samples, the heat transfer coefficient as $h=87.91 \mathrm{~W} / \mathrm{m}^{2} \mathrm{~K}$ and the heat transfer coefficient as $k=0.187 \mathrm{~W} / \mathrm{mK}$ were determined for $B i=4$ according to the experimental data. Figure 3 shows the temperature distribution graph obtained as a result of the experiments for changing the central temperature in the hazelnut. According to the studies on this subject can be continued hazelnut varieties and sizes.

During drying, the central temperature changes in the thin exhibition hazel party, the values according to the exhibition entrance and exit temperatures, and the changes in the drying air depending on the drying air speed and humidity, are shown in Figures 4-8.

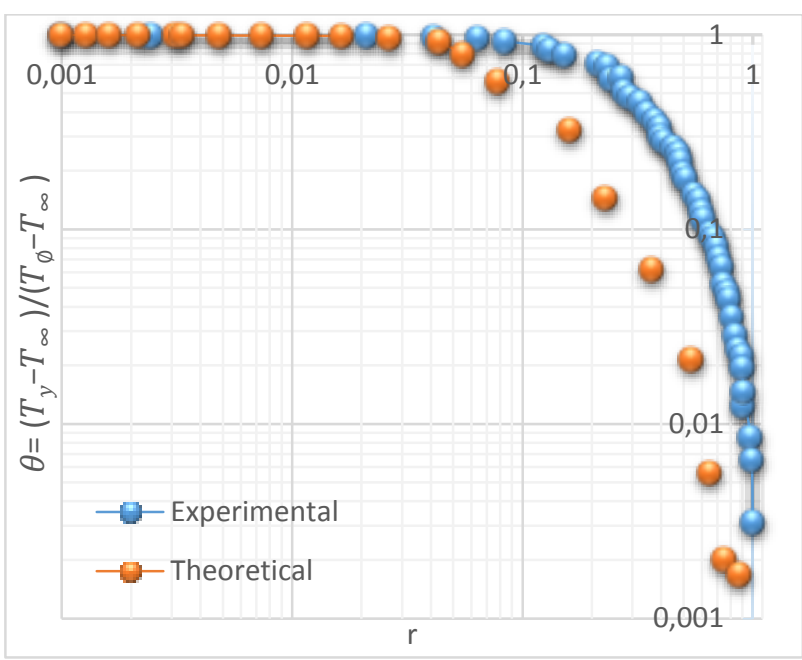

Figure 3. Temperature distribution in hazelnut.

The graph obtained for equilibrium moisture measurements of hazelnut samples is given in Figure 9.

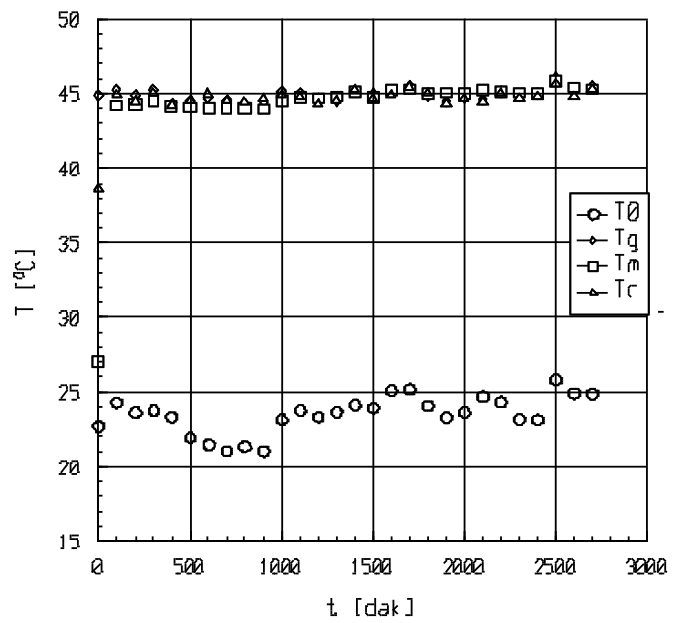

Figure 4. Change of experimental drying air and hazelnut center temperature $\left(\mathrm{T}_{\mathrm{g}}=45^{\circ} \mathrm{C}, \mathrm{u}=0.3 \mathrm{~m} / \mathrm{s}\right.$, $\emptyset=0.65)$

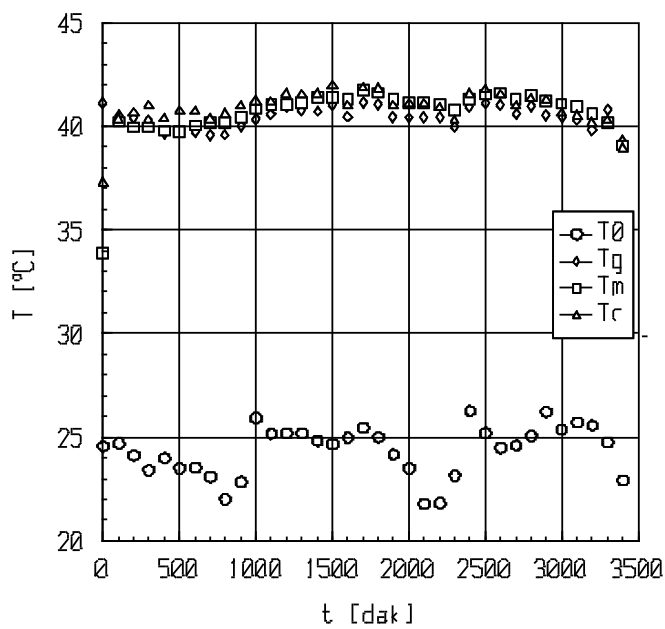

Figure 5. Change of experimental drying air and hazelnut center temperature $\left(T_{g}=40^{\circ} \mathrm{C}, u=0.3 \mathrm{~m} / \mathrm{s}\right.$, $\emptyset=0.65)$ 


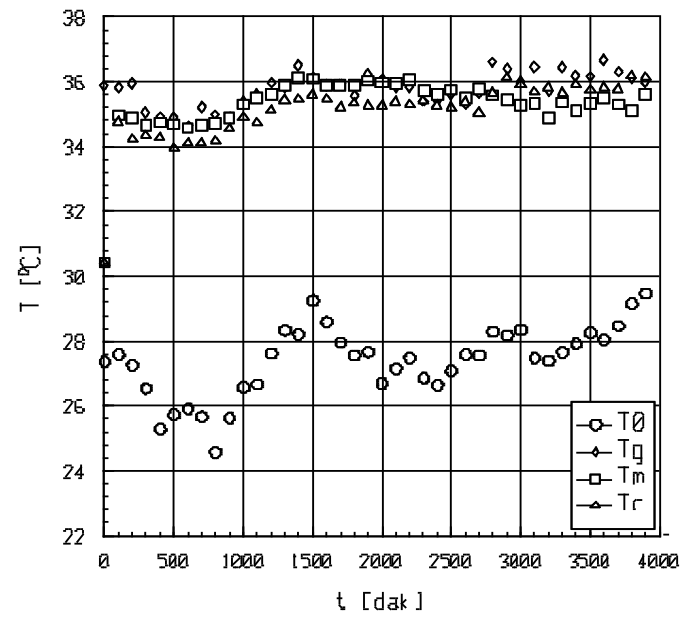

Figure 6. Change of experimental drying air and hazelnut center temperature $\left(T_{g}=35^{\circ} \mathrm{C}\right.$, $u=0.3 \mathrm{~m} / \mathrm{s}, \emptyset=0.65$ ).

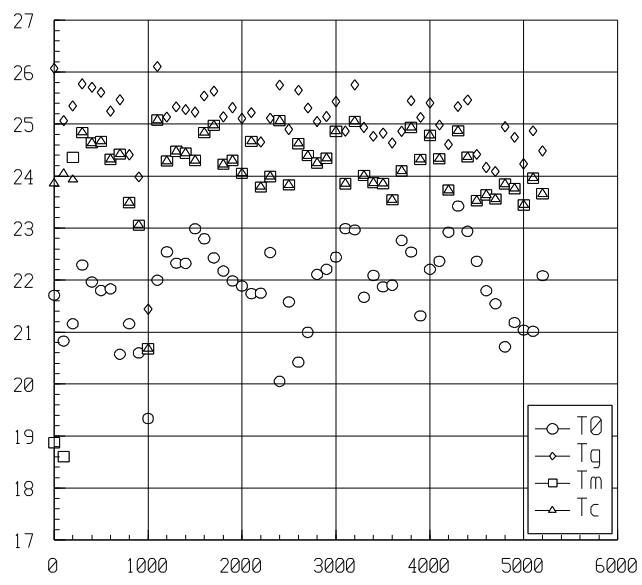

$t[\mathrm{dak}]$

Figure 7. Change of experimental drying air and hazelnut center temperature $\left(T_{g}=25^{\circ} \mathrm{C}\right.$, $u=0.3 \mathrm{~m} / \mathrm{s}, \varnothing=0.65$ )

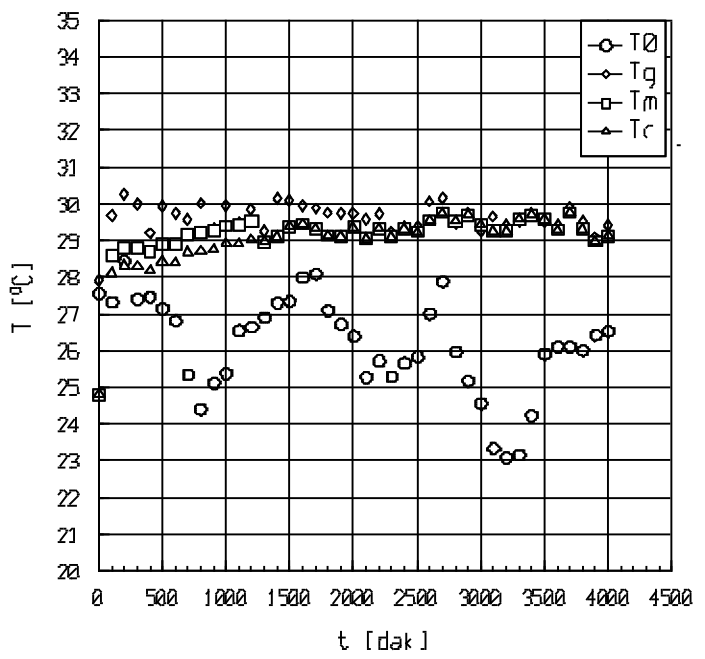

Figure 8. Change of experimental drying air and hazelnut center temperature $\left(T_{g}=30^{\circ} \mathrm{C}\right.$, $u=0.3 \mathrm{~m} / \mathrm{s}, \varnothing=0.65$ )

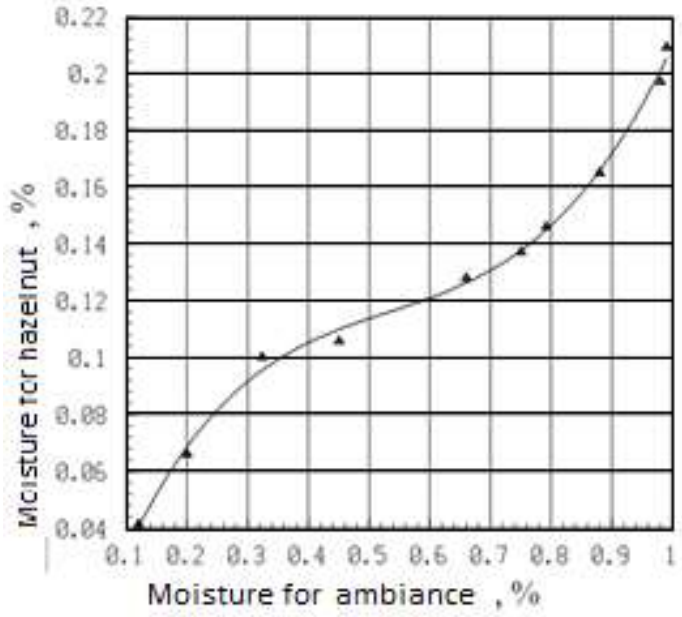

Figure 9. The equilibrium moisture curve for plump hazelnut $\left(T=20^{\circ} \mathrm{C}\right)$.

At various temperatures of the drying air, the change in the time of the nuts in the hazelnut part $\left(\mathrm{M}_{\mathrm{av}}-\mathrm{t}\right)$ is given in Figure 10 for a $65 \%$ relative humidity and a $0,3 \mathrm{~m} / \mathrm{s}$ rate. It has been observed that the results obtained with the experiments performed in this study are in close agreement with the mathematical model used for temperature distribution in hazelnut (layered sphere). The compatibility of experimental and theoretical work is shown in Figure 3.

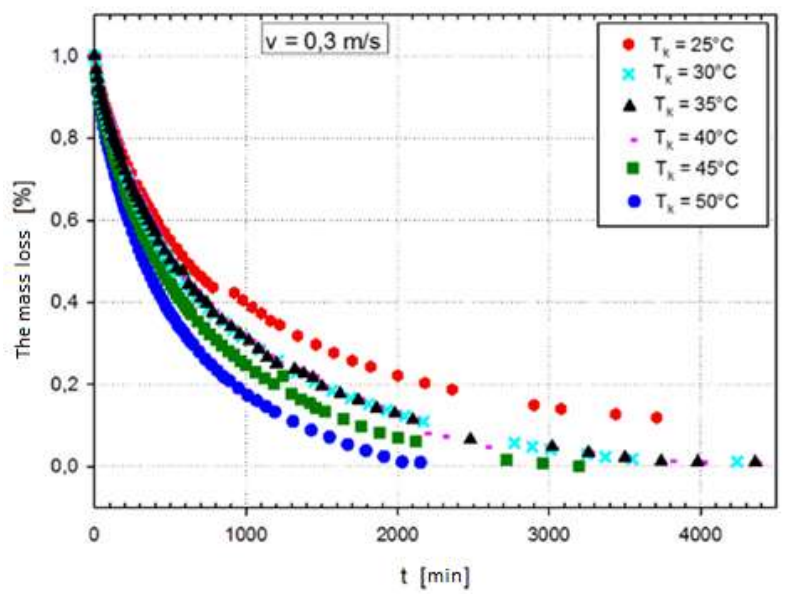

Figure 10. $M_{a v}$-t changes in hazelnut $(l=0.60, u=0,3$ $\mathrm{m} / \mathrm{s}$ )

In the study, drying of hazelnut at $60 \%$ relative humidity, $0.3 \mathrm{~m} / \mathrm{s}$ speed and 25, 30, 35, 40, 45 and $50^{\circ} \mathrm{C}$ air temperatures were discussed. At the time of drying, the temperature of the drying air at the outlet and the center temperatures showed a fall in the first time depending on the temperature of the inlet product and the latent heat of vaporization, but later this difference only appeared due to evaporation latent heat. This is seen in Figures 4, 5, 6. 7 and 8. The increase in air temperature reduces the drying period and increases drying speed, 
weight loss and percentage of nematode plotted against time (Figure 10). During the same drying period in columns where the drying air velocity is great, over hardening in the hazelnut kernel and gaps in the center of the inner hazelnut have occurred. Dried hazelnuts should be around $6 \%$. This seems to have occurred at about $20 \%$ ambient air humidity. The ambient air will also increase the balance of the waste ash. It is seen that the nut is changing very rapidly in the equilibrium humidity when it exceeds $65 \%$ of the humidity of ambient air.

\section{Conclusions}

The results obtained in experiments with air humidity of $65 \%$ relative humidity, air velocity of $0,3 \mathrm{~m} / \mathrm{s}$ and air temperatures of 25, 30, 35, 40, 45 ${ }^{\circ} \mathrm{C}$ were interpreted in fine view.

As the temperature of the drying air is high, the drying time is reduced and the drying speed is increased, while the initial times of weight reduction are rapidly decreasing, the reduction rate is slowing down to the balance amount of moisture in those conditions. It has been shown that the mathematical model introduced for the determination of heat transfer parameters in nuts can be used to determine the thermodynamic properties of hazelnuts. The mathematical model established with the experimental data obtained in the drying of the pomegranate nuts very well. It has been shown that the drying characteristics of hazelnut can be determined when the temperature of the drying air, the product balance nemesis and the moisture content of the product are known. Our recommendations are to determine the thermodynamic properties of hazelnut based on all hazelnut species. Investigation of the effects of drying conditions on hazelnut storage properties in artificial drying.

\section{Author Statements:}

- The authors declare that they have equal right on this paper.

- The authors declare that they have no known competing financial interests or personal relationships that could have appeared to influence the work reported in this paper

- The authors acknowledge that the preliminary study of this article is presented in " $4^{\text {rd }}$ International Conference on Computational and Experimental Science and Engineering (ICCESEN-2017)"

\section{References}

[1] Marti, Joan Tous. "World hazelnut production". Available online at:(accessed 11 March 2003),
2001

[2] Hoffman, Richard, and Mariette Gerber. "Food processing and the Mediterranean diet".

Nutrients 7.9 (2015): 7925-7964.

[3] Pannico, A., et al. Non-destructive detection of flawed hazelnut kernel sand lipid oxidation assessment using NIR spectroscopy. Journal of Food Engineering 160, 2015, 42-48.

[4] Mercanligil, S. M., et al. "Effects of hazelnutenriched diet on plasma cholesterol and lipoprotein profiles in hyper cholesterolemic adult men." European Journal of Clinical Nutrition 61.2 (2007): 212.

[5] Yucesan, F. B., et al. "Hazelnut consumption decreases the susceptibility of LDL to oxidation, plasma oxidized LDL level and increases the ratio of large/small LDL in normolipidemic healthy subjects. Anadulu Kardiyoloji Dergisi: AKD 10.1 (2010): 28.

[6] Dutta, S. K., V. K. Nema, and R. K. Bhardwaj. "Drying behaviour of spherical grains". International journal of heat and mass transfer 31.4 (1988): 855-861.

[7] Steffe, J. F., and R. P. Singh. "Diffusion coefficients for predicting rice drying behaviour." Journal of Agricultural Engineering Research 27.6 (1982): 489-493.

[8] Keey, R. B. Drying of loose and particulate materials. CRC Press, 1991.

[9] Gröber, E. G. Warmeübertragung; 3. Auflage, Springer-Verlag, Berlin-Heidelberg, New York, 1963

[10] Keey, R. B., and M. Suzuki. "On the characteristic drying curve." International Journal of Heat and Mass Transfer 17.12 (1974): 1455-1464.

[11] Daloğlu, A., Çok katmanlı kürede geçici rejimde ısitransferinin nümerik hesaplanması, Yüksek lisans tezi,. KTU, Trabzon, 1982

[12] Ünal, A. and Daloğlu, A., Küresel şekilli kompozit cisimlerde usl transferi, 10. Ulusal Is1 Bilimi ve Tekniği Kongresi, Ankara, 1995, 139148

[13] Demirtas, C., Teoman A., and Kaygusuz, K., "Drying behaviour of hazelnuts." Journal of the Science of Food and Agriculture 76.4 (1998): 559-564.

[14] Kaya, A. Aydın, O. and Demirtaş, C., "Experimental and theoretical analysis of drying carrots." Desalination 237.1-3 (2009): 285-295. 